\title{
One Frog in a Well? Many Frogs in Many Wells!
}

\author{
Stefan Peiffer $^{1}$
}

Eingegangen: 1. Dezember 2016 / Online publiziert: 26. Januar 2017

(c) Springer-Verlag Berlin Heidelberg 2017

Ein Frosch, der sich in seinem Brunnen wohlfühlt und nicht die Großartigkeit der Welt außerhalb seines gemütlichen „Bohrlochs“ wahrnimmt. Damit hat Frank Schwartz in seinem Gast-Editorial die deutsche Hydrogeologie verglichen, die er anlässlich unserer Jahrestagung in Bayreuth 2014 sozusagen live erleben durfte.

In die Nussschale gepackt begründet er den Vergleich damit, dass sich die deutsche Hydrogeologie zu wenig der Komplexizität der Wasserforschung geöffnet habe, namentlich der Kopplung des Grundwassers an aquatische und terrestrische Ökosysteme im Hinblick auf Energie-, Massenund Stoffflüsse. Sie begnüge sich mit im Grunde sehr speziellen oder lokalen Aspekten.

An dieser Stelle möchte man dagegenhalten und erwidern, dass das doch eigentlich gar nicht stimmt und sich beleidigt ins Bohrloch zurückziehen, sich wundernd, dass auf einmal mehr oder auch weniger Wasser als früher zuströmt (Klimawandel), dass das Grundwasser schmutziger wird (Landnutzungswandel), dass also irgendwas da draußen vorgeht, und mit dem Grundwasser in Wechselwirkung tritt (Konnektivität).

Ich würde jedoch sagen: der Mann hat recht! Aber dies betrifft ganz sicher nicht nur die Hydrogeologie, sondern alle Disziplinen der deutschen Wasserforschung und sogar darüber hinaus gehende Fächer. Um es überspitzt zu formulieren: Die Wasserchemiker betreiben Wasseranalytik, die Limnologen studieren die Wasserlebewesen, die Bodenhydrologen verbleiben in der obersten Zone der Geosphäre, die Hydrologen ignorieren das Grundwasser usw. Viele Brunnen und viele Frösche und alle sind glücklich.

Es gibt nach wie vor keine systemübergreifende Wasserforschung in Deutschland, deren wissenschaftliche Basis die Erkenntnis ist, dass Energie-, Massen- und Stoffflüsse, ja Informationsflüsse keine Systemgrenzen kennen. Ein Lichtblick ist da sicherlich die Implementierung der Water Science Alliance, die sich explizit für die Zusammenführung der Disziplinen und der Bündelung von Synergien einsetzt. Es ist kein Zufall, dass eine Initiative für ein DFGSchwerpunktprogramm an der Grenze zwischen Geo- und Biowissenschaften ihren Ausgang bei der Water Research Horizon Conference nahm, der alljährlich stattfindenden Konferenz der Water Science Alliance zum Austausch über die großen Themen der Wasserforschung. Das Thema des Schwerpunktprogramms: Quantifizierung von Evapotranspiration - ein physiologisch/mikrometeorologisches Thema mit immenser Auswirkung für die Grundwasserneubildung!

Vor diesem Hintergrund war die FH-DGGV sicherlich gut beraten, Mitglied bei der Water Science Alliance zu werden. Sie hat damit klar zum Ausdruck gebracht, dass ihr daran gelegen ist, aus dem Brunnen auszubrechen und die Welt mit neuen Augen zu sehen.

Stefan Peiffer

s.peiffer@uni-bayreuth.de

1 Universität Bayreuth, Bayreuth, Deutschland 